\title{
ENSAYOS
}




\section{LOS IGNORANTISTAS Y LAS ESCUELAS — LA OPOSICION A LA REFORMA EDUCATIVA DURANTE LA FEDERACION COLOMBIANA ( $\left.{ }^{*}\right)$}

Por Jane M. Loy ${ }^{* *}$

Colombia experimentó la "edad de oro" de la educación primaria durante la época del Federalismo (1863-1886) ${ }^{1}$. En 1870 el Presidente Eustorgio Salgar promulgó el Decreto Orgánico de la Instrucción Pública Primaria, que creó por primera vez en Colombia un sistema nacional uniforme de educación secular obligatoria. Durante la década siguiente, el gobierno fundó veinte escuelas normales para entrenar maestros de escuela primaria; estableció el Directorio General de Instrucción Pública como una oficina administrativa central con oficinas regionales en cada uno de los nueve Estados; adoptó un nuevo currículo basado en los últimos conceptos pedagógicos alemanes; y compró en París millares de libros de texto y de mapas para distribuir en las escuelas. En el apogeo de la Reforma, en 1870, asistían a clase más de 79.000 estudiantes entre niños y niñas en 1.649 escuelas primarias en todo el país ${ }^{2}$.

La campaña para la instrucción primaria fue sólo una faceta de un extenso programa que había institucionalizado la facción radical del partido liberal en la Constitución de 1863. Sin embargo, el Decreto Orgánico tocó aspectos que no eran bien vistos por la aristocracia dado que ignoraba las lealtades partidistas y, en cierto modo, exaltaba las masas. Su éxito inicial se debió en gran parte al enérgico apoyo de los instruccionistas, un grupo compuesto no sólo por Radicales, sino también por muchos sacerdotes y aun algunos conservadores que vieron en la educación de masas la clave para el progreso de Colombia. Igualmente, enérgicos fueron otros conservadores, sacerdotes y liberales que miraban la escuela oficial como anatema y por causa de su oposición se granjearon el epíteto de ignorantistas ${ }^{3}$. La agitación causada por la educación alcanzó el clímax en la guerra civil de 1876-1877, que sumió a la mayor parte del área montañosa de Colombia en la confusión y forzó la suspensión de las escuelas públicas. A pesar de los esfuerzos de los instruccionistas por revivir el movimiento después de que la paz había sido restaurada, las escuelas declinaron continuamente y el Decreto Orgánico se convirtió en letra muerta. Aunque el fracaso de la reforma no se le puede asignar totalmente a la resistencia de los ignorantistas, un análisis de sus argumentos contra el Decreto Orgánico y de las tácticas que utilizaron para derrotarlo podrá sugerir algunos de los obstáculos que tuvo que confrontar el cambio educativo en Colombia a fines del siglo XIX.

\footnotetext{
* Este artículo es una versión ligeramente revisada de una ponencia leída en la Convención Anual de la Asociación Americana de Historia en Boston, Massachussets, en diciembre de 1970.

** Profesora de Historia de Massachussets en Amherst.

${ }^{1}$ Luis Antonio Bohórquez Casallas, La evolución educativa en Colombia, (Bogotá, 1956), p. 525.

${ }^{2}$ Informe del Director General de Instrucción Primaria de la Unión (Bogotá, 1876). De acuerdo con el censo de 1869, Colombia tenía una población de aproximadamente tres millones de personas. El número de alumnos matriculados era todavía bajo, pero estos totales aún admitiendo errores sustanciales, representan una ganancia considerable en relación con la década anterior.

${ }^{3}$ El Diario de Cundinamarca usó por primera vez el término ignorantista en junio 29 de 1872 en respuesta a las acusaciones de José Manuel Groot, quien en una serie de articulas publicadas en el diario conservador, Caridad, se refirió a los reformadores como instruccionistas. El Diario definió el término como "un adepto del ignorantismo; es decir, el estado de ignorancia o de todo lo que tiene por objeto el favorecerlo".
} 
Como el Decreto Orgánico era defendido por los Radicales no es de sorprender que muchos conservadores lo encuentran objetable desde el punto de vista político y moral ${ }^{4}$. Habiendo sido derrotados en las guerras de 1860-61, los conservadores se encontraban débiles y desorganizados durante los 'primeros años del Federalismo. Un consenso creciente en materia educativa y otros tópicos les ayudó a restaurar la unidad del partido. En 1876 los conservadores estaban ya lo suficientemente fuertes como para iniciar un ataque militar contra el gobierno federal. Aunque perdieron la guerra, continuaron ganando apoyo para su programa, uniéndose a los liberales desencantados dirigidos por Rafael Núñez para derrocar El Olimpo Radical en 1886.

A finales del siglo XIX casi todos los gobiernos europeos y americanos expresaban al menos en teoría sus deseos de expandir la educación pública. Dada la presencia de estos desarrollos en el país, los conservadores, no podían abiertamente oponerse a la idea misma de la Reforma de la escuela sin aparecer por ello como anacrónicos. Después de 1865 las plataformas del partido defendieron consistentemente el establecimiento de la educación primaria y secundaria gratis, como el mayor deber social de un pueblo cristiano y republicano ${ }^{5}$. Los conservadores, sin embargo, matizaban esta exigencia insistiendo en que toda educación debe ser moral, religiosa, bien dirigida, práctica y adecuada a las costumbres colombianas ${ }^{6}$. Cuando evaluaban el Decreto Orgánico de acuerdo con estos parámetros, una gran cantidad de conservadores encontraban razones infinitas para alarmarse.

En primer lugar, argüían que el sistema centralizado aprobado por el Decreto violaba la Constitución que los mismos radicales habían redactado. La Constitución de 1863 garantizaba a los gobiernos federales y estatales el derecho a fomentar la instrucción pública ${ }^{7}$. El artículo I del Decreto decía que el gobierno federal, "organizaría, dirigiría e inspeccionaría la instrucción primaria pública", en los Estados que ratificara el Decreto ${ }^{8}$. Los conservadores argumentaban que "fomentar" no significaba "organizar y dirigir" y mucho menos "centralizar". "Fomentar" significaba "auxiliar", una acción que estaba completamente de acuerdo con el espíritu Federal de la Constitución. Por el contrario, el gobierno nacional se estaba constituyendo en dictador de la instrucción pública. La centralización era ineficiente y rayaba en el absoluto. El gobierno estaba imponiendo parámetros uniformes que eran más apropiados para una monarquía prusiana que para una república democrática9 ${ }^{9}$. La educación pública era deber de los Estados y era su responsabilidad el asegurar que los distritos locales fundaran y mantuvieran las escuelas ${ }^{10}$.

Los conservadores denunciaron el artículo 87 del Decreto Orgánico que hacía obligatoria la instrucción para todos los niños entre las edades de siete y quince años. Basaron su objeción en la Sección 11, artículo 15 de la Constitución, que garantizaba a todo colombiano la libertad de "dar y recibir cualquier clase de instrucción en instituciones

\footnotetext{
${ }^{4}$ Es importante notar que algunos conservadores apoyaron el Decreto Orgánico, como lo demostré en Modernización y Reforma educativa en Colombia, ("Modernization and Educational Reform in Colombia, 1863-1886), tesis doctoral no publicada, Universidad de Wisconsin, 1969. Tal vez el mejor ejemplo fue Manuel Mallarino, expresidente conservador que fue el primero en ocupar el cargo de Director General de Instrucción Pública. La mayoría de los conservadores, sin embargo se oponían al Decreto, si no por razones políticas, por lo menos por razones religiosas y sociales.

${ }^{5}$ Lo Voz de la Patria, I (Bogotá), febrero 6 de 1865.

${ }^{6}$ El Deber (Bogotá), I, octubre 15 de 1878.

${ }^{7}$ William Marion Glbson, The Constitutions of Colombia (Durham, 1948), p. 278.

${ }^{8}$ Decreto Orgánico de Instrucción Pública Primaria, reimpreso en Anuario de la A.N. de Ciencias de la Educación, II Bogotá, 1936, p. 51 y en la Revista Colombiana de Educación, No. 5, Bogotá, I. semestre de 1980.

${ }^{9}$ Caridad (Bogotá), VII, Octubre 12 de 1871, pp. 308-312.

${ }^{10}$ El Heraldo (Medellín), III, octubre 27, 1871, p. 583. 
que no estuvieran mantenidas con fondos públicos ${ }^{11}$. Forzar a los niños a ir a escuelas públicas era un "crimen patente" contra las libertades individuales, los derechos de los padres y la libertad del maestro. Como decía un escritor, el individuo era libre de tal manera, que era libre de ser ignorante y nadie podía forzarlo a instruirse ${ }^{12}$.

La promulgación de la educación secular provocó las críticas más serias al Decreto Orgánico. El artículo 36 decía:

El gobierno no interviene en la instrucción religiosa; pero las horas de escuela se distribuirán de manera que a los alumnos, les quede tiempo suficiente para que, según la voluntad de sus padres, reciban dicha instrucción de los sacerdotes o minis$\operatorname{tros}^{13}$.

De acuerdo con la separación entre Iglesia y Estado previamente establecida, el Decreto no requería que las escuelas oficiales ofrecieran clases de religión, ni estipulaba que los profesores fueran católicos. Permitía a los sacerdotes, a solicitud de los padres, dar instrucción religiosa dentro de las escuelas como actividad extra-curricular. A pesar de esta concesión, la omisión del catecismo constituyó una verdadera revolución educativa en Colombia. Los conservadores reclamaban que si el gobierno no autorizaba la instrucción religiosa, estaba violando la voluntad mayoritaria de la población. Sacar la religión de la educación era crear una educación falsa ${ }^{14}$. Los extremistas formularon la acusación de que el Decreto era un complot liberal para atrapar la juventud y que el gobierno estaba convirtiendo las escuelas en "talleres" para transformar a los niños en "esclavos sumisos de las ambiciones liberales y de las pasiones bastardas"15. Bajo las promesas rosadas del Decreto Orgánico decían, había veneno. Sólo la Iglesia podía supervisar adecuadamente la instrucción oficial. Sin religión, los niños se convertirían en "criaturas de un proletariado ateo", una generación sin fe, sin calor filial, y sin conocimiento verdadero ${ }^{16}$.

Un tema sustancial de la protesta conservadora era que la instrucción laica infundiría el descontento en las clases bajas. El gobierno no parecía darse cuenta de que si la gente era mala bajo la influencia de la religión, sería aún peor sin sus prohibiciones; tendría pasiones incontroladas. Al final los colombianos serían corrompidos, turbulentos e incapaces de hacer el bien ${ }^{17}$. La educación secular era una invitación al desastre. Roma había caído ante los bárbaros porque les faltaba un fundamento moral fuerte. Bajo el impacto de la Internacional Comunista, los franceses se habían vuelto capaces sólo de matar, quemar iglesias y adherirse a la comuna. Claramente cualquier pueblo que descartara la noción de un Dios, un alma y la inmortalidad, abrazaría finalmente una ideología subversiva ${ }^{18}$. Hacia 1880 los conservadores pudieron distinguir triunfalmente los malos efectos acumulados por la educación secular. El crimen aumentaba en efecto proporcionalmente a la extensión de las escuelas públicas. Muy pronto, predecían, los maestros se convertirían en sacerdotes del socialismo y diariamente las orgías de sangre remplazarían a la civilización y al orden ${ }^{19}$.

\footnotetext{
${ }^{11}$ Gibson, The Constitution of Colombia. p. 277.

${ }^{12}$ El Deber, I (enero 21 de 1879).

${ }^{13}$ Decreto Orgánico, p. 60.

${ }_{15}^{14}$ El Tradicionista. Bogotá, I. junio 18 de 1872, p. 284.

${ }^{15}$ Manuel Briceño. La Revolución 1876-1877: recuerdos para historia. (2a. ed.) Bogotá, 1947, p. 183.

${ }^{16}$ El Tradicionista, II, febrero 1 de 1873, pp. 632-633.

${ }^{17}$ Ibid., I. junio 15 de 1872 , p. 279.

${ }^{18}$ Caridad. VII, septiembre 14 de 1871, p. 241-250.

${ }^{19}$ El Bien Social, Bogotá, Serie IV, enero 23 de 1880, p. 131.
} 
Además de mantener una avalancha de propaganda anti-escuela en la prensa, que iba desde quejas razonadas hasta denuncias histéricas de los reformadores como ateos, masones, instruccionistas, corruptores y asesinos, los conservadores también propusieron alternativas al Decreto Orgánico. En 1872, por ejemplo, el senador Sergio Arboleda propuso sin éxito una ley para exigir que todas las escuelas oficiales dieran instrucción religiosa y que todos los maestros fueran católicos ${ }^{20}$. Otros dirigentes apoyaron planes para traer a los Hermanos Cristianos a Colombia. Estas comunidades de hermanos legos manejaban escuelas católicas libres en toda Europa lo mismo que en el país vecino del Ecuador y en Chile. Los hermanos eran excelentes maestros, verdaderamente religiosos y no buscaban ganancias personales. Los conservadores urgieron la creación de sociedades privadas que recogieran dinero para mantener a estas escuelas sin alcanzar mucho éxito ${ }^{21}$. A pesar de los esfuerzos considerables de algunos ciudadanos privados, los Hermanos Cristianos no vinieron a Colombia.

Los extremistas exhortaron al público a exigir educación religiosa y a boicotear las escuelas, aun en el caso de que esta táctica llevara a una rebelión abierta contra el gobierno. En el Cauca, Tolima y Antioquia, sociedades católicas locales se movilizaron para defender la Iglesia y para proteger la educación religiosa. Estas sociedades enviaron peticiones a Bogotá declarando que las escuelas oficiales eran un complot masónicoliberal, un insulto a los católicos y una medida diseñada para destruir la religión verdadera $^{22}$. Algunas de ellas mantenían con fondos propios escuelas privadas voluntarias que ofrecían instrucción católica ${ }^{23}$. Cuando el candidato conservador perdió las elecciones presidenciales de 1875, ante su adversario radical Aquileo Parra, muchos de sus adeptos estaban preparados para usar la educación laica como un medio de ganarse el apoyo popular para la guerra civil de $1876^{24}$.

Tres obispos y un gran número de sacerdotes, pidieron al Arzobispo de Bogotá, Vicente Arbeláez, fortalecer a los conservadores en su campaña contra las escuelas. Como era típico de muchos católicos sinceros, Arbeláez había aconsejado la cooperación con el Decreto Orgánico por consideración al objetivo fundamental de la ilustración popular. El Arzobispo no aprobaba muchos aspectos del Decreto, pero creía que la Iglesia podía mitigar sus peores efectos alentando a los sacerdotes a usar su derecho legal de atender las escuelas ${ }^{25}$.

Carlos Bermúdez, el Obispo de Popayán, se opuso fuertemente a esta posición conciliatoria y fue apoyado por los Obispos de Medellín y de Pasto. Estos hombres confirmaron la acusación conservadora, de que las escuelas colombianas caían bajo la condena papal de la educación laica en las proposiciones XLVII y XLVIII del Syllabus of Errors publicado en 1864. Argüían que mientras el gobierno rehusara reconocer la autoridad de la Iglesia, poco importaba que se permitiera a los sacerdotes enseñar religión como actividad extra-curricular. Los obispos convinieron en que el Decreto Orgánico era un complot liberal, posiblemente masón, para arruinar a los niños y aniquilar a la Iglesia ${ }^{26}$.

\footnotetext{
${ }^{20}$ El tradicionista, I marzo 12 de 1872. p. 153.

${ }^{21}$ Ibid., I, mayo 9 de 1872, p. 218.

${ }^{22}$ La Regeneración, Bogotá, I, julio 6 de 1876, p. 48.

${ }^{23}$ Memorias del Secretario del Interior y de Relaciones Exteriores de los Estados de Colombia para el Congreso de 1874. (Bogotá, 1874) p. 57.

${ }^{24}$ Constancio Franco y., Apuntamientos para la historia de la guerra de 1876-1877. (Bogotá, 1877). p. 21.

${ }^{25}$ Para una discusión de la posición del Arzobispo, véase, Jane Meyer Loy "Modernization and Educational Reform in Colombia", 1863-1886. pp. 168-173.

${ }^{26}$ Gonzalo Uribe U. Los Arzobispos y Obispos Colombianos desde el tiempo de la Colonia hasta nuestros días. (Bogotá, 1918$)$ p. 80.
} 
A comienzos de la década de 1870 los prelados disidentes iniciaron una cruzada contra el Decreto Orgánico. Bermúdez, promulgó una carta pastoral en la que excomulgaba a los católicos que matriculasen a sus hijos en las escuelas públicas y ordenaba a los sacerdotes boicotear las escuelas ${ }^{27}$. En el Segundo Concilio Provisional de Obispos Colombianos de 1874, rompió públicamente con el Arzobispo en relación con la educación religiosa y pidió una intervención del Vaticano en la disputa ${ }^{28}$. Mientras esperaba la decisión del Papa, hizo lo que pudo para impedir la Reforma en Popayán, prohibiendo en una ocasión a los estudiantes que asistían a clase en las escuelas normales públicas, que participaran en las procesiones de Semana Santa ${ }^{29}$. Manuel Canuto Restrepo, Obispo de Pasto, promulgó seis cartas pastorales protestando contra el Decreto Orgánico, describiendo el pecado cometido por los padres que enviaran a sus hijos a la escuela pública. Su carta fechada en octubre 12 de 1872, comparaba al padre que llevaba a su hijo a la escuela con el Abraham Bíblico que sacrificó a su propio hijo. De acuerdo con Restrepo, la única diferencia entre los dos actos era que los colombianos además de llevar a sus hijos al altar, pagaban el sueldo del verdugo. Esta carta levantó una reacción popular tan fuerte que el Presidente del Cauca estuvo forzado a declarar un rompimiento del orden público el 2 de diciembre de $1872^{30}$.

Muchos sacerdotes en toda Colombia, pero especialmente en el Cauca, Tolima y Antioquia, respondieron a las admoniciones de los obispos. Rehusaron enseñar religión en las escuelas públicas o aceptar responsabilidades en la administración de Instrucción Pública. Algunos como el cura de Bolívar (Cauca), trataron de persuadir a los maestros a que renunciaran, advirtiéndoles que participaban en la ruina espiritual de los niños ${ }^{31}$. Otros, incluyendo un cura de Tunja, condenaban al censo escolar y ordenaban a los padres esconder a sus hijos en vez de dejar que fueran contados ${ }^{32}$. Un sacerdote en Popayán, declaró un domingo que los estudiantes que fueran a la maldita escuela pública serían atacados por la viruela. Al día siguiente, no pocas personas visitaron los salones de clase para constatar si los estudiantes habían contraído la enfermedad ${ }^{33}$. Un maestro de esa misma ciudad reportó en 1876 que su clase se había reducido a tres alumnos porque los sacerdotes locales habían dicho a los padres:

Si enviáis a vuestros hijos a estas escuelas pagadas por el gobierno, no podréis recibir perdón por vuestros pecados; absolutamente careceréis de los beneficios espirituales $^{34}$.

La advertencia fue muy efectiva porque el profesor continúa:

Me parece, señor, que para gente como ésta, la amenaza es suficiente y en obediencia a la autoridad ya mencionada, han retirado a sus hijos de este establecimiento, aunque estén convencidos en sus propias mentes de su inocencia ${ }^{35}$.

El Decreto Orgánico que dividió a la jerarquía católica fue también un tema de división dentro del campo de los liberales. Muchos liberales estaban desencantados con la

\footnotetext{
${ }^{27}$ Ibid., p. 82.

${ }^{28}$ José Restrepo Posada, Arquidiócesis de Bogotá: datos biográficos de sus prelados (Bogotá, 1966), III, p. 124.

${ }^{29}$ José María Quijano Wallis. Memorias: autobiografías históricas, políticos y de carácter social. (1919), p. 219.

${ }^{30}$ Mensaje del Presidente del Estado del Cauca a la Legislatura de 1873 (Popayán, 1873), p. 4.

${ }^{31}$ EL Escolar. Popayán II. Abril 27 de 1876, p. 541.

${ }^{32}$ Escuela Normal. Bogotá IV, enero 18 de 1873.

${ }^{33}$ Quijano Wallis, Memorias p. 220.

${ }^{34}$ El Escolar. II Abril 27 de 1976, p. 495.

${ }^{35}$ ibid.
} 
camarilla radical que dominaba la Federación, con el extremismo de la Constitución de 1863, y especialmente, con las severas medidas que había sancionado el gobierno federal contra la Iglesia. Por la década de 1870 los disidentes habían organizado una nueva facción que tomó el nombre de Independientes. En la elección presidencial de 1875, desdeñaron al candidato Radical para apoyar a uno de su escogencia, Rafael Núñez. A diferencia de los Radicales que endosaban con entusiasmo el Decreto Orgánico, los Independientes tenían profundas dudas sobre una educación centralizada, obligatoria y secular.

José María Samper representó el punto de vista Independiente. Siendo Radical durante los primeros años de la Federación, Samper le dio la bienvenida al Decreto Orgánico cuando se anunció por primera vez y aun apoyó una escuela de niñas en Ubaque (Cundinamarca) con su propio dinero. Sin embargo, hacia 1874 confesó que aunque nadie tenía más entusiasmo que él por la instrucción pública, había llegado a la conclusión que el Decreto Orgánico era inconstitucional ${ }^{36}$. Con el pretexto de promover la educación el Congreso la había absorbido y monopolizado creando una burocracia inmensa e interfiriendo en la jurisdicción de los Estados ${ }^{37}$. Samper creía que el gobierno debía renunciar a la centralización dejando a los Estados libres para organizar las escuelas públicas de acuerdo con sus propios puntos de vista. Igualmente detestable para su filosofía liberal era el concepto de instrucción obligatoria. El gobierno debía poner a la disposición de los ignorantes las instalaciones educativas, pero no debía abusar de su autoridad forzándolos a asistir a clase ${ }^{38}$.

Samper acusó a los Radicales de extender la discusión sobre la educación secular más allá de límites realistas. Al alegar que la religión no era un asunto oficial y que por lo tanto no se podía ofrecer religión en las escuelas públicas, los Radicales habían impuesto lo que constituía una educación "irreligiosa" sobre un pueblo que era esencial y unánimemente cato-lico. Samper urgió al gobierno a reconocer los derechos de los padres que exigían que las escuelas financiadas por sus impuestos debían dar a sus hijos una instrucción que estuviera en armonía con su fe católica ${ }^{39}$.

Los argumentos de Samper, con su énfasis en la descentralización administrativa y las libertades individuales, lo revelan, más que a los Radicales, como el heredero del credo liberal clásico. A pesar de su "liberalismo", en la década de 1870 Samper estuvo en mayor armonía con los conservadores moderados que con los miembros de su propio partido. Así, en 1877, colaboró como Independiente con el dirigente Conservador Carlos Holguín en la publicación de un periódico, El Deber. Al año siguiente completó su metamorfosis política al elaborar la plataforma oficial del partido conservador ${ }^{40}$. Por esta época, un número creciente de liberales había desertado de las fuerzas Radicales para unirse a los Independientes. El desacuerdo en la oligarquía dirigente ayudó en gran manera a debilitar el apoyo Federal al Decreto Orgánico. En 1880 los Independientes y los conservadores formaron una coalición para elegir como presidente a Rafael Núñez. Dos de sus primeros actos fueron reformar el Directorio General de Instrucción Pública y debilitar la prohibición contra la educación religiosa en las escuelas públicas. De allí en adelante, la instrucción primaria dejó de ser punto de discusión en el gobierno y las escuelas comenzaron a deteriorarse.

\footnotetext{
${ }^{36}$ Diario de Cundinamarca (Bogotá), VI (Mayo 12 de 1874), p. 633. Citado de ahora en adelante como DC.

${ }^{37}$ La Ley (Bogotá). Tri. II. num. 25 (enero 10 de 1876), p. 98.

${ }^{38}$ La Unión Colombiana (Bogotá), Tri., I, núm. 9 (febrero 6 de 1875), pp. 91-92.

${ }^{39}$ El Polverín (Bogotá), Tri. I, num. 312 (enero 27 de 1876), pp. 91-92.

${ }^{40}$ El Deber, I (octubre 15 de 1878), p. 18.
} 
Los conservadores disidentes, los Independientes y el clero, bloquearon de manera efectiva la reforma con sus continuas contribuciones de hipérbole periodística contra el Decreto. De igual manera, como miembros de la legislatura estatal, rehusaron votar en favor de los fondos para las escuelas. Algunas veces pasaron leyes que regulaban la educación, pero no hicieron ningún esfuerzo por hacerlas cumplir. Ignoraron los impuestos destinados al apoyo financiero de las escuelas y rehusaron servir de funcionarios de instrucción local ${ }^{41}$. Medardo Rivas, un periodista Radical y fluido crítico social, observaba en 1873 que era la gente acomodada, la aristocracia, la que hacía una guerra implacable a las escuelas, porque ellos tenían sus propios intereses y no sentían ninguna vinculación con el pueblo ${ }^{42}$.

Sin embargo, no toda la resistencia contra el Decreto Orgánico venía de los estratos sociales superiores. Aunque no eran estrictamente hablando ignorantistas, un término que se refería principalmente a la élite antagonista de las escuelas, otros dos grupos apoyaron sus puntos de vista. Los "gamonales" (jefes políticos locales) y la gran masa de colombianos conocida como "la gente del pueblo", no se expresaron en el Congreso o en la prensa, pero su apabullante antipatía por las escuelas fue notada debidamente por los empleados del gobierno y por observadores no oficiales.

El sociólogo colombiano Orlando Fals Borda ha definido el término gamonal como un funcionario público, terrateniente, o sacerdote, cuya posición en la sociedad le permite ejercer influencia sobre los residentes de un sitio y organizar la maquinaria para perpetuarse en el poder ${ }^{43}$. Desde la Independencia, estos dirigentes locales parecían haber desestimulado la expansión de la educación popular. Como David Bushnell lo nota en El Régimen de Santander en la Gran Colombia, un factor que contribuyó a la decadencia de las escuelas de Lancaster en la década de 1820 fue "la laxitud e indiferencia de muchos funcionarios de provincia que no compartían el celo del gobierno nacional"44. En la década de 1860, casi todos los Estados habían reconocido la necesidad de tener instrucción pública, y habían pasado leyes que exigían el mantenimiento de una escuela en cada distrito. Con la posible excepción de Antioquia, los distritos no se preocuparon por actuar de acuerdo con estas medidas ${ }^{45}$. La implementación del Decreto Orgánico se enfrentaba a un cuello de botella semejante. A pesar de la colaboración de unos pocos dedicados dirigentes distritales, la mayoría de las autoridades locales resistieron los esfuerzos federales por llevar la educación al pueblo.

Algunos comentaristas atribuían la actitud de los gamonales a un deseo de mantener lo que era para ellos un favorable status quo. En 1872 el Diario de Cundinamarca, principal órgano de la opinión radical en Bogotá, informaba que en las áreas rurales hombres que sabían algo se habían impuesto sobre los otros. Estos hombres no querían escuelas que hicieran desaparecer la desigualdad intelectual ${ }^{46}$. Medardo Rivas escribió que una "oligarquía indolente" que criticaba cada gasto y reforma decretados por el gobierno era un gran obstáculo para la difusión de la instrucción popular ${ }^{47}$. Notaba que los gamonales combatían las escuelas para poder preservar su autoridad tradicional:

\footnotetext{
${ }^{41}$ El Bien Público (Bogotá), No. 4 (marzo 15, 1873), p. 26.

${ }^{42}$ Revista de Colombia (Bogotá), V. (marzo 15 de 1873). p. 26.

${ }^{43}$ Orlando FaIs Borda, Peasant Society in the Colombian Andes (Gainesville 1955), p. 2.

${ }^{44}$ David Bushnell, The Santander Régime in Gran Colombia (Newark, 1954) p. 186.

${ }^{45}$ Comenzando en la década de 1860, bajo la dirección del presidente Conservador Recaredo de Villa, Antioquia comenzó a expandir la educación primaria sin ninguna ayuda federal y tenía en 1870 el mejor sistema de escuelas públicas en la Federación.

${ }^{46}$ DC, III (mayo 31 de 1872).

${ }^{47}$ Revista de Colombia, V. (marzo 15 de 1873), p. 26.
} 
La ignorancia les ha ayudado a obtener esta influencia local y por esta razón resulta la triste situación de hombres que no tienen ni virtud ni patriotismo que ejercen su dominación tan lamentablemente y que no tienen interés en la propagación de la educación ${ }^{48}$.

Un informe del Jefe del Departamento de Norte, Antioquia, reiteraba un tema similar, que los gamonales en esa provincia estaban oponiendo una resistencia perniciosa a la educación en tal forma que las ideas nuevas no pudieran llegar a las clases sociales ignorantes $^{49}$. El Director de Instrucción Pública del Cauca explicaba que la reacción negativa de los alcaldes en ese Estado era comprensible, teniendo en cuenta que siendo ellos mismos ignorantes, no podían juzgar lo que no sabían, oír lo que no entendían, ni ver lo que no podían comprender ${ }^{50}$. El Jefe de Moreno (Boyacá) presentó la descripción más pesimista de todas al describir el cabildo de un pueblo en su región:

El cabildo de Casanare está compuesto por hombres rústicos e ignorantes que no pueden comprender el beneficio más inmediato que cualquier rama de un buen servicio público les pueda dar, y consideran como un martirio, como una mala estrella, como una predestinación fatal, el arte de aprender a leer y a escribir. ¿Qué clase de protección será dada a la educación primaria por esta clase de hombres $?^{51}$.

Los gamonales no lograron completar ni siquiera la primera y fundamental etapa de la reforma, la tabulación de un censo escolar. En 1872 el Director de Instrucción Pública del Tolima notaba que los alcaldes, debido a su ignorancia y a la falta de asistentes, habían sido incapaces de presentar una cuenta de los niños en edad escolar en sus distritos ${ }^{52}$. Desde Magdalena, el Director escribía que a pesar de repetidos decretos y circulares, sólo quince de cuarenta y un distritos habían tomado el censo ${ }^{53}$. Un letargo generalizado hizo confesar al Director General en 1874 que su oficina en Bogotá no había recibido datos suficientes de los Estados para calcular el número de niños en edad escolar en Colombia ${ }^{54}$.

El colapso de la inspección escolar se puede también atribuir a la falta de cooperación local. De acuerdo con el Decreto Orgánico, los padres y las autoridades de cada población debían constituir una comisión de vigilancia para asegurar el progreso de las escuelas. En la década de 1870, una de las quejas más frecuentes de los Directores estatales era la falta de funcionamiento de estas comisiones. En Bolívar, el Director observaba que la inspección era irregular ya que los funcionarios del municipio cumplían deficientemente con sus deberes o no cumplían ${ }^{55}$. El Director del Magdalena decía que las comisiones no entendían la confianza que se les había dispensado y que había varios distritos en los que no se estaba haciendo ninguna inspección ${ }^{56}$. En 1873 el Director General resumió el impase cuando escribió: "nada es tan unánime como los informes de indolencia y mal funcionamiento de las comisiones y de los funcionarios responsables de la inspección escolar"

\footnotetext{
${ }^{48}$ Ibid., II (agosto 20 de 1869), p. 153.

${ }^{49}$ Memoria que presenta al Ciudadano Presidente del Estado S. de Antioquia el Secretario de Gobierno y Guerra 1883 (Medellín, 1883) p. 20.

${ }^{50}$ Diario Oficial (Bogotá), XX (julio 28 de 1884), pp. 136-47.

${ }^{51}$ El Boyacense (Tunja). III (agosto 18 de 1868), p. 522.

${ }^{52}$ Escuela Normal, IV (enero 18 de 1873).

${ }^{53}$ Ibid., V (enero 10 de 1874), p. 11.

${ }^{54}$ Ibid.

${ }^{55}$ Ibid., V (enero 24 de 1874), pp. 22-23.

${ }^{56}$ Ibid.

${ }^{57}$ Ibid, IV (enero 18 de 1873), p. 21.
} 
Un incidente en el Cauca demuestra claramente cómo la falta de interés local obstaculizaba la reforma. En 1873 la legislatura del Estado aprobó una apropiación que dividía doce mil pesos entre distritos pobres para el mantenimiento de las escuelas públicas. Después de un año, el Director anunciaba que la medida había sido virtualmente inoperante. Sólo dos distritos habían solicitado fondos, y los otros cabildos, o no sabían cómo solicitar el dinero o eran demasiado indolentes para estimular a sus distritos a que lo pidieran ${ }^{58}$. Aun cuando el dinero estaba disponible para la instrucción pública, muchos distritos dejaron de beneficiarse por falta de dirección calificada.

El carácter recalcitrante de las autoridades locales complicó el trabajo de los maestros. El Director de Boyacá escribía que los alcaldes ignoraban las quejas de los maestros sobre la poca asistencia de los alumnos. Para cubrir su fracaso en el intento de imponer la asistencia obligatoria, denunciaban más bien a los maestros ${ }^{59}$. En Magdalena el Director reportaba que en los municipios no apropiaban los fondos de las escuelas y que mostraban negligencia en el recaudo de impuestos. Los maestros tenían que exigir el pago de sus salarios. A veces los funcionarios rehusaban pagarles aun cuando tuvieran el dinero ${ }^{60}$. El Director de Bolívar atribuía la baja asistencia a las escuelas a la apatía de los Concejos Municipales que no ofrecían los edificios y materiales requeridos por ley ${ }^{61}$. En algunos casos las autoridades locales inclusive alentaban a los ciudadanos a boicotear las escuelas. El Prefecto de Antioquia Central afirmaba que el clero y los gamonales estaban urgiendo a los padres a hacerle la guerra a las escuelas ${ }^{62}$. En 1882 El Promotor, el periódico independiente más importante de Barranquilla, explicaba por qué se había alcanzado tan poco progreso:

"No se necesita ir más lejos para ver que los Alcaldes del Distrito, los Concejos Municipales y las Juntas de Instrucción Pública, miran la Instrucción Pública con gran indiferencia, dejando con frecuencia de asistir a los exámenes de las escuelas y falsificando después los informes requeridos por la $l e y^{63}$.

Bajo estas condiciones es difícil imaginarse cómo un maestro mal entrenado y mal pagado podía cumplir con su "santa misión" de llevar luz al pueblo.

Igualmente fatal para la reforma escolar, fue la oposición del grupo amorfo al que en ocasiones se llamaba "la gente del pueblo", la "clase desvalida" o "la clase menos acomodada". Era para este grupo, la gran mayoría de los colombianos, para el que las escuelas creadas por el Decreto Orgánico se habían destinado. Las masas por supuesto no tuvieron que ver con la adopción de las nuevas leyes ni con el debate casuístico mantenido por los miembros de la aristocracia. Sin embargo, los comentarios de los funcionarios de las escuelas y de otros observadores, sugieren que si se hubiese tomado en cuenta el deseo popular no se hubiera dado una reforma educativa.

Desde un comienzo los pobres opusieron resistencia a la educación formal porque les exigía hacer unos sacrificios económicos más allá de sus posibilidades. El niño campesino era un sirviente no remunerado. Desde temprana edad llevaba agua, buscaba leña,

\footnotetext{
${ }^{58}$ El Escolar, I (noviembre 5 de 1874), p. 59.

${ }^{59}$ Informe anual del Director de Instrucción Pública del Es lado Soberano de Boyacá (Tunja, 1874), p. 19.

${ }^{60}$ Informe del Director General de Instrucción Primaria de la Unión (Bogotá, 1876), p. 651.

${ }^{61}$ Diario de Bolivar (Cartagena), XXIII (agosto 30 de 1880).

${ }^{62}$ Memoria que presenta al Ciudadano Presidente del Estado S. de Antioquia el Secretario de Gobierno y Guerra, 1883 (Medellín, 1883), p. 26.

${ }^{63}$ El Promotor (Barranquilla), XII (noviembre 25 de 1882).
} 
cuidaba los cerdos y espantaba a los pájaros de los cultivos ${ }^{64}$. Si asistía a la escuela, no había quién hiciera estas tareas; más aún, los padres no podían alimentar a un niño improductivo. No le podían comprar el vestido y los libros necesarios. Muchos vivían tan lejos de una escuela que no podían llegar a la clase sino después de caminar varias horas. Como observaba un funcionario en Santander, la mayoría de los padres en su región vivían a más de una legua de un pueblo con escuela y muchos a cuatro o cinco leguas. Y añadía "todos prefieren dedicar sus familias a la cosecha del café, que hoy día tiene un precio muy alto, a enviar a sus hijos a las escuelas"65.

Mucha gente creía que la educación no tenía valor para sus hijos. Las materias que aprendían en la escuela no les ayudaba en el campo. A pesar de los esfuerzos del gobierno, los maestros estaban todavía mal preparados y utilizaban métodos, anacrónicos. Los niños perdían su tiempo memorizando hechos que olvidaban en cuanto se terminaba la clase. En 1872 Dámaso Zapata, uno de los principales defensores de la reforma y quizá el más destacado educador colombiano de la época, admitía que era notorio que estudiantes que durante los exámenes hacían las sumas más difíciles, fuera de la escuela eran incapaces de resolver los más simples problemas de la vida. Dándose cuenta de esta realidad, los padres retiraban a sus hijos de las escuelas y rehusaban prestar cualquier cooperación ${ }^{66}$.

Como se sugirió antes, mucha gente fue movida por las admoniciones del clero a rehuir las escuelas por razones religiosas. En el Cauca un maestro informaba que los padres temían enviar a sus hijos a la escuela porque el cura no daba su aprobación a los textos con los que se impartía la enseñanza ${ }^{67}$. Un funcionario de Boyacá observaba que los sacerdotes ordenaban a los padres esconder a sus hijos, antes que matricularlos en las escuelas que los transformarían en soldados o protestantes ${ }^{68}$. El Director del Tolima atribuía la mala asistencia a "los sermones de los párrocos que son enemigos de la instrucción, o tal vez demasiado perezosos para enseñar las clases de religión" 69 . En 1876 el Diario de Cundinamarca admitió que los padres no cuestionaban la infalibilidad del Papa o la de sus Obispos, pero que sin sanción eclesiástica no enviarían sus hijos a la escuela $^{70}$.

Otra razón de la apatía popular era la conciencia de que la educación traía pocos beneficios tangibles al niño campesino. Un maestro de escuela en Panamá escribía con disgusto que los padres se contentaban con ver a sus hijos crecer "como arbolitos" ${ }^{11}$. Otro se quejaba:

Es sencillamente imposible hacerles entender que la educación es necesaria. Los padres dicen que ellos no han ido a la escuela y que les va bien. Más tarde sus hijos vivirán igual sin la ayuda de la escuela ${ }^{72}$.

\footnotetext{
${ }^{64}$ El Maestro de Escuela (Bogotá), II (enero 6 de 1874), p 481.

${ }^{65}$ La Escuela Primaria (Socorro). II (julio 31 de 1873), p. 279.

${ }^{66}$ Escuela Normal. IV (enero 18 de 1873).

${ }^{67}$ El Escolar. II (julio 20 de 1882).

${ }^{68}$ Informe del Secretario General al Presidente del E.S. de Boyacá, año de 1873 (Tunja, 1873), p. 15.

${ }^{69}$ El Constitucional (Ibagué), VIII (agosto 26 de 1875), p. 1.604.

${ }^{70}$ DC. VII (abril 24 de 1876), p. 565.

${ }^{71}$ Gaceta de Panamá. (Panamá), I (septiembre 1o. de 1870).

${ }^{72}$ Gaceta de instrucción Pública (Panamá), I (noviembre 14 de 1874).
} 
Un tercer profesor confirmaba la indiferencia popular:

La gente prefiere ver a sus hijos vagando por las calles, adquiriendo malas costumbres, diciendo palabras que ofenden la moral, faltando al respeto a sus mayores, haciendo cosas que no son propias de su edad, antes que hacerlos asistir regularmente a las escuelas ${ }^{73}$.

Algunos padres parecen haber interpretado la fundación de las escuelas como un acto hostil perpetrado contra ellos por el gobierno. Un maestro escribió en 1874 que la gente creía que enseñar a un niño a leer y a escribir era el equivalente a enseñarle a robar ${ }^{74}$ - El Director de Boyacá informaba que la gente en todos los pueblos no quería que sus hijos se volvieran "doctores" y preferían que fueran trabajadores honrados ${ }^{75}$. Había un miedo persistente de que la instrucción volvería a los hijos contra sus padres. Un campesino le decía a Dámaso Zapata: "Si llevo mis hijos a la escuela, nunca volverán porque el día en que sepan mas que yo, serán mis enemigos" ${ }^{\prime 76}$. Un funcionario de Boyacá trató de explicar por qué la posibilidad de ser capaz de leer y escribir evocaba tal antagonismo. Los rústicos, escribía, no podían entender el valor de la educación. Combatían las escuelas porque eran a menudo las víctimas de tinterillos semiinstruidos. Y concluía:

Los niños en el pueblo son educados, mientras los niños del campo permanecen ignorantes. Como no hay carreras industriales o comerciales para la juventud, es claro que los niños de los pueblos se convertirán en tinterillos y agitadores que exploten a la masa ignorante ${ }^{77}$.

Los pobres expresaban su oposición a las escuelas uniéndose a las Sociedades Católicas, pero había también actos de hostilidad más flagrantes. En Zaque (Cundinamarca) una escuela rural fue incendiada intencionalmente dos veces en el mismo año ${ }^{78}$. En 1872 el maestro de escuela de Funza (Cundinamarca) informaba que mientras había estado fuera de su casa una mujer había entrado allí a la fuerza, amenazando con matarlo, gritó que era un impostor, un protestante y un masón y que eso era lo que el cura había dicho. Al no encontrarlo salió a la calle y le tiró piedras a la casa. Después trató de volver a entrar escalando el muro de un edificio adyacente ${ }^{79}$. Estos incidentes eran poco comunes pero ocurrían. Hay también evidencia que durante la Guerra Civil de 1876 mucha gente desfogó su ira contra las escuelas. Fuerzas rebeldes que marchaban bajo banderas religiosas llevaban estandartes que pedían la educación católica ${ }^{80}$.

Los soldados convertían los salones en barracas. Algunos destruían intencionalmente los libros, materiales de enseñanza, muebles y aún los edificios. En Santander un funcionario informó que el equipo de la escuela había sido atacado con "ferocidad inhumana" $"$.

La reacción popular más típica, sin embargo, fue simplemente ignorar la escuela. El "ethos de pasividad" la actitud de resignación, docilidad y fatalismo inculcados en el pueblo por las inflexibles condiciones de la era colonial y reafirmadas en el siglo XIX,

\footnotetext{
${ }_{73}^{73}$ El Bien Público, II (octubre 10 de 1871) p. 69.

${ }^{74}$ Gaceta de instrucción Pública (Panamá), I (noviembre 14 de 1874).

${ }^{75}$ Informe del Secretado General al Presidente del E.S. de Boyacá año de 1873 (Tunja, 1873).

${ }^{76}$ Escuela Normal, I. (Marzo 25 de 1871), p. 177.

${ }_{77}^{77}$ Gaceta de Panamá, XI (mano 3 de 1882).

${ }^{78}$ Informe del Director General de Instrucción Primaria de la Unión (Bogotá, 1876) p. 186.

${ }^{79} \mathrm{DC}$, III (julio 16 de 1872), 872.

${ }^{80}$ Briceño, La revolución, p. 183.

${ }^{81}$ Gaceta de Santander (Socorro), XXII (mayo 7 de 1880) p. 133.

Digitalizado por RED ACADEMICA
} 
llegaron a ejercer una gran presión contra el cambio educativo ${ }^{82}$. La gente rehusaba enviar sus hijos a la escuela al mismo tiempo que los escondía de los empadronadores. Ignoraban los ruegos de los funcionarios de instrucción y no le hacían caso a las multas y amenazas de sanción. Simplemente continuaban como antes, dedicando toda su energía a sostener la vida misma ${ }^{83}$.

Es claro que a pesar del progreso inicial de las escuelas a comienzos de la década de 1870, la mayoría de los colombianos se opuso al Decreto Orgánico. La adopción de la educación centralizada, obligatoria y secular se convirtió en un punto político de discusión muy conveniente para los que no estaban contentos con el control de los Radicales. El Decreto Orgánico ofendió a muchos católicos sinceros que se mostraban reacios a apoyar una educación "inmoral" y a un clero resentido que miraba a la Iglesia como una fortaleza asediada por el anticlericalismo. Se puede argüir que si los Radicales hubiesen hecho concesiones en esta materia de la educación secular, hubieran neutralizado a sus oponentes más virulentos. Pero este paso era prácticamente inconcebible ya que uno de los principales objetivos de su programa era el quebrar el poder de la Iglesia; pero aun si hubiesen incluido el catecismo en el currículo oficial, hay poca evidencia que indique que las escuelas hubiesen tenido más éxito. En la década de 1880, cuando Rafael Núñez enmendó el Decreto Orgánico para restaurar la integridad católica de las escuelas, no hubo ningún entusiasmo público. Es necesario concluir que bajo las objeciones religiosas de la aristocracia, existía un miedo mucho más profundo a un proletariado frustrado que supiera leer y escribir y desafiara el orden tradicional. Uno se pregunta qué tan inmunes serían aún los Instruccionistas a la amenaza de un populacho indócil e incitado. Es irónico que el sujeto de estos temores, la "gente del pueblo", miraba a las escuelas con un recelo aún mayor, observando correctamente que la educación formal, sea religiosa o de otra clase, no tenía ningún sentido en el contexto de su vida diaria. Así pues, el Decreto Orgánico, producto de la "efervescencia intelectual" generada por el optimismo y desilusión de una larga era de liberalismo, como el resto de la legislación de los Radicales, obtuvo una respuesta negativa que fluctuaba entre brillantes ataques verbales y una muda apatía ${ }^{84}$.

Más aún, el intento quijotesco de establecer una educación secular obligatoria entregó a los Ignorantistas un arma poderosamente efectiva para explotar el descontento político, religioso y social en la Federación Colombiana.

\footnotetext{
${ }^{82}$ FaIs Borda, Peasant Society, p. 245.

${ }^{83}$ La República (Bogotá), 1. (Febrero 27 de 1878).

${ }^{84}$ J. León Helguera "The problem of Liberalism versus Conservatism inColombia: 1849-85" en Frederick B. Pike, (ed.) Latin American history: Select Problems (New York, 1969) p. 256.
} 